\title{
Subsídio público à oferta educacional privada: reflexões a partir do modelo irlandês ${ }^{1}$
}

\section{Public subsidy for private educational supply: reflections from the irish model}

Subsidio público a la oferta educativa privada: reflexiones a partir del modelo irlandês

\section{THERESA MARIA DE FREITAS ADRIÃO JULIANA DE PAULA EDUARDO AZEVEDO}

\begin{abstract}
Resumo: Fruto de pesquisa de natureza exploratória, em fontes documentais primárias e secundárias e em entrevistas, o artigo investiga o modelo irlandês de acesso à educação obrigatória, que se assenta na escolha parental de escolas, organiza-se sem a presença de escolas estatais e garante a gratuidade. Com base em estudos sobre privatização, indica-se, na forma de fechamento não conclusivo, contradições decorrentes de seleção praticada pelas escolas e limites aos tipos de escolas "disponíveis" na região de Dublin como inibidores para a escolha, suscitando o aprofundamento de estudos sobre esses formatos, no contexto de ampliação desse modelo associado a interesses corporativos.
\end{abstract}

Palavras-chave: financiamento, escolha parental, escolas privadas.

\begin{abstract}
The article explores the Irish model of access to compulsory education using exploratory research from primary and secondary sources and interviews. The model is based on the choice of schools by families, which is organized without the presence of state schools, even though the educational offer is free. Based on the findings of the preliminary research the model reveals its contradictions resulting from the selection criteria practiced by the schools and the limits perceived by the interviewers with the types of schools available in the Dublin area. As a result, further analysis of these formats is relevant especially within the context of the broadening corporate interests in education globally.
\end{abstract}

Keywords: funding, parental choice, private schools

Resumen: Fruto de investigación de naturaleza exploratoria, en fuentes documentales primarias y secundarias y en entrevistas, el artículo investiga el modelo irlandés de acceso a la educación obligatoria, basado en la elección parental de escuelas, se organiza sin la presencia de escuelas estatales, y garantiza la gratuidad. Basado en los estudios sobre privatización, se indica, en la forma 
de cierre no conclusivo, las contradicciones derivadas de selección practicada por las escuelas y de los límites a los tipos de escuelas "diponibles" en la región de Dublín, como inhibidores para la selección, suscitando la profundización de estudios sobre estos formatos, en el contexto de ampliación de ese modelo asociado a intereses corporativos.

Palabras clave: financiación, elección parental, escuelas privadas.

\section{INTRODUÇÃO}

Este artigo resulta de pesquisa qualitativa, de cunho exploratório, apoiada em levantamento de informações em fontes primárias e em entrevistas com mães de estudantes que se encontravam matriculados em escolas irlandesas, localizadas em Dublin, na etapa obrigatória. O trabalho contou ainda com aporte da literatura sobre o tema investigado.

Segundo o Dicionário de Sociologia Moderna (1970), organizado por Theodorson e Theodorson, os estudos exploratórios cumprem a função de ampliar o grau de informação sobre determinado objeto, permitindo ao pesquisador elaborar, com mais qualidade, hipóteses para o desenvolvimento de investigação futura e escolher os mais adequados procedimentos metodológicos. Além disso, pesquisas exploratórias auxiliam os pesquisadores a entender melhor o fenômeno estudado, quando se identifica ausência de informações suficientes sobre o tema. Para Polit, Beck e Hungler (2004), esse tipo de estudo permite elaborar descrições mais detalhadas dos fenômenos, etapa necessária ao desenvolvimento da pesquisa sobre temas pouco conhecidos.

Tratou-se, pois, de uma aproximação sistemática ao objeto investigado com vistas a fornecer elementos para a composição de um quadro de referência teórico-metodológica a respeito dos modelos de financiamento público a escolas de educação obrigatória geridas privadamente.

Este tema atrela-se a estudos anteriormente desenvolvidos (suprimido, 2014, 2017) a respeito de programas de subsídio público à oferta educacional privada ${ }^{2}$, os quais, na última década, recebem o apoio de movimentos organizados e de corporações, inclusive em âmbito mundial, alicerçados na defesa da primazia da escolha das famílias pela escola de seus filhos, sobre sua oferta estatal e na desqualificação da oferta educacional pelo Estado (EDWARDS JUNIOR; HALL, 2017; suprimido, 2014).

2 Ver Suprimido (2014); Suprimido (2017), Suprimido (2018). 
Trata-se de movimentos de "advocacy" pró escolha parental (choice) como o National School Choice Week nos EUA, potencializados por fundações privadas e partidos políticos conservadores que passam a disputar a agenda educacional em diferentes contextos, inclusive no Brasil (KLEES et al, 2012; PATRINOS; BARRERA-OSORIO; GUÁQUETA, 2009; ADRIÃO; 2009, 2017). Tais orientações, entendidas por parte da literatura como formas de privatização da oferta educativa (entre tantos, Apple, 2003 e Scott, 2009 para os EUA, Lubienski e Yoon, 2017 - Canadá; Adrião, 2009 e 2017; Freitas, 2015; Domiciano; 2012- Brasil), assentam-se na substituição da oferta educacional estatal pela ampliação de programas de escolha parental financiados por fundos públicos.

No entanto, o modelo de oferta educacional irlandês, embora figure como referência de sistema educacional alicerçado na "escolha parental" (FOX, BUCHANAN; 2008), é pouco tratado pela literatura em geral.

O Gráfico 1 indica a proporção com que o tema da escolha de escolas foi tratado no conjunto dos trabalhos inventariados em pesquisa junto ao $W e b$ of Science ${ }^{4}$, para o período de 1990-2015. O inventario considerou os artigos em periódicos relacionados à educação obrigatória localizados por meio do descritor CHOICE presente em seus títulos ou resumos, sendo condição para a inclusão no levantamento bibliográfico, a existência desse último.

\footnotetext{
3 Estudos mais sistemáticas sobre o tema da escolha parental para diversos contextos encontram-se em Lubienski (2011) Lubienski e Lee (2017) e OCDE (2014 e 2012).

4 Web of Science (Web-S) é uma plataforma de acesso a referencias que agregou o ISI- Web Knowledge, constituída por mais de 12 mil fontes e gerida pela Thomson Reuters Scientific. O acesso se deu por meio do link. wokinfo.com acessado com o login da CAPES durante entre 2015 e 2016.
} 


\section{Gráfico 1 - Incidência de publicações com resumo disponíveis no WEB of Science/ISI- descritor CHOICE- 1990-2015}

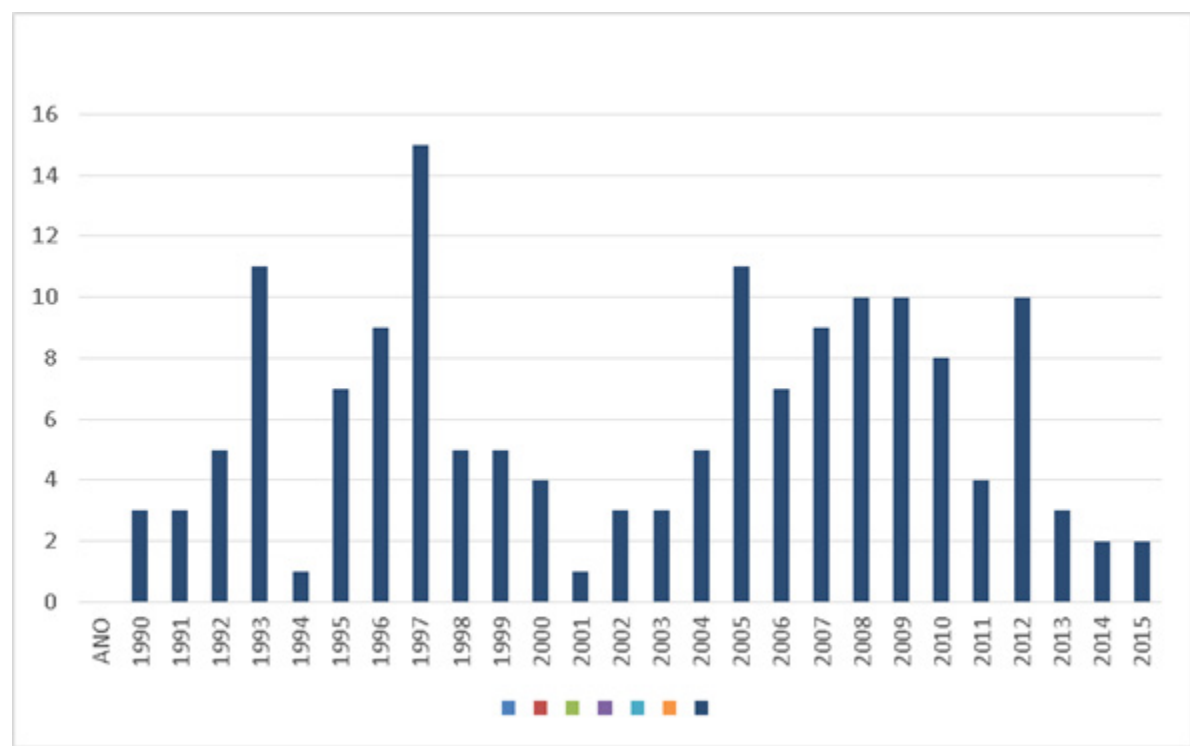

Do total de artigos encontrados com o descritor, 193 associavam-se ao campo EDUCATION ou EDUCATIONAL RESEARCH; desses, 70 se referiam à educação em sua etapa obrigatória, cf. gráfico 1 , mas apenas dois analisavam a situação da Irlanda: Lynch e Moran (2006) e Buchanan e Fox (2008).

Lynch e Moran (2006) problematizam estudos que não consideram sincronicamente as políticas de escolha da escola com a ampliação do discurso neoliberal e o crescimento do mercado global da educação. Complementarmente, para os autores, as escolas têm identidades e são identificadas em função da classe social que as frequenta, de modo que escolas que tradicionalmente atendam grupos de baixa renda, dificilmente alteram essa identidade, mesmo se alterados o grupo social que as frequenta e suas taxas de desempenho acadêmico. O contrário também se verifica: escolas que foram pagas, ao se tornarem gratuitas ainda atraíam estudantes de classe média. Reconhecem, entretanto, que não havia por parte do Estado, incentivos que associassem o 'direito de escolha' a estratégias de competição entre escolas, mas alertam para tendências de crescimento do setor privado com fins de lucro, incentivado pelo repasse de fundos públicos, especialmente no nível secundário, etapa não retratada neste artigo. 
Em posição diametralmente oposta encontrou-se o artigo de Buchanan e Fox (2008), no qual se analisa o sistema irlandês em diálogo com o modelo de charter school estadunidense. Para os autores, a 'escolha' e a 'liberdade', medidas pela capacidade dos pais de selecionarem as escolas de seus filhos, estão profundamente enraizadas no ethos nacional dos Estados Unidos. Entretanto, se os pais americanos ricos sempre exercitaram a escolha da escola, o mesmo não ocorre com os estudantes de minorias e de baixa renda, os quais, muitas vezes, ficam limitados a frequentar escolas de pior qualidade. O texto sobre a natureza da escolha da escola pautou-se em pesquisa conduzida junto a uma amostra intencional de escolas primárias irlandesas. Os autores examinam cinco aspectos do sistema nacional irlandês de ensino primário, que poderiam fornecer modelos para educadores americanos, cuja visão muitas vezes para nas fronteiras dos Estados Unidos: lei da educação, mecanismos de escolha da escola, estrutura curricular nacional, o papel da avaliação, e o papel dos pais e educadores na criação de novas escolas.

Em outro trabalho, os mesmos autores informam que o compromisso da Irlanda com a escolha da escola expressa-se tanto em políticas de admissão à escola, inclusive por não se pautar na matrícula georreferenciada, quanto na possibilidade de as famílias optarem por escolas com distintas orientações confessionais, focadas na língua irlandesa (gaélica), multiconfessionais ou, ainda, pela educação domiciliar (FOX; BUCHANAN; 2008).

Por matrícula georreferenciada entendem-se os procedimentos que atrelam a escola de destino a áreas geograficamente definidas, em geral, em função do local de residência do estudante. Na maioria dos casos, o atendimento associase à distribuição dos fundos públicos resultantes de impostos. Esse procedimento foi identificado em pesquisa realizada nos estados norte-americanos de Maryland e Georgia, dado serem os Estados Unidos que disseminam trabalhos (ARCHBALD, 2004) e movimentos da sociedade civil defensores do fim do georreferenciamento e da introdução de programas de escolha da escola como mecanismo para que famílias pobres rompam ciclos de desigualdade na oferta educacional, instituídos pela obrigatoriedade de matricular os filhos nas escolas dos bairros em que moram.

O texto se organiza em três partes: informações sobre a organização da educação obrigatória na Irlanda, com destaque para as formas praticadas pelas escolas para a matrícula dos estudantes; análise das entrevistas coletadas e indicações finais.

As informações foram coletadas entre 2016-2018, por meio de pesquisa documental em sítios oficiais do Department of Education and Skills (DES) e demais órgãos governamentais e em notícias divulgadas em jornais irlandeses. 
Complementarmente coletou-se, por meio de entrevistas semiestruturadas gravadas ou registradas ${ }^{5}$, o depoimento de cinco mães de estudantes matriculados em escolas primárias ou pós primrias distribuídas pela região metropolitana de Dublin.

\title{
NOTAS SOBRE A ORGANIZAÇÃO DO SISTEMA EDUCACIONAL IRLANDÊS
}

\author{
$\mathrm{Na}$ Irlanda, a escolha da escola pelos pais é um direito definido \\ constitucionalmente, no Artigo 42:
}

1. O estado reconhece a família como educador primário e natural da criança e garante e respeita o direito inalienável e dever dos pais para fornecer, de acordo com seus meios, a educação religiosa e moral, intelectual, física e social de seus filhos. 2 Pais devem ser livres para fornecer essa educação em suas casas, em escolas privadas ou em escolas reconhecidas ou estabelecidas pelo Estado. $31^{\circ} \mathrm{O}$ estado não obriga os pais a violarem sua consciência pela preferência legal no envio de seus filhos para escolas estabelecidas pelo Estado, ou a qualquer tipo específico de escola designado pelo Estado. $2^{\circ}$ o Estado, no entanto, como guardião do bem comum, exige que as crianças recebem uma mínima educação, moral, intelectual e social. 4 - o estado deve fornecer educação primária de graça e envidar esforços para completar e dar auxílio razoável para iniciativa educacional particular e, quando o bem público o exigir, fornecer outros equipamentos escolares ou instituições, considerando, no entanto, os direitos dos pais, especialmente em matéria de formação religiosa e moral. ${ }^{6}$ (Constitution of Ireland - tradução livre do autor)

$5 \quad$ As entrevistas seguiram as normas éticas para sua realização e foram autorizadas por termo de consentimento assinado pelas entrevistadas, os quais encontram-se arquivados.

6 Texto atualizado original da Constituição da Irlanda, disponível em $<$ http://www.irishstatutebook. ie/eli/cons/en\#article42

1 The State acknowledges that the primary and natural educator of the child is the Family and guarantees to respect the inalienable right and duty of parents to provide, according to their means, for the religious and moral, intellectual, physical and social education of their children.

2 Parents shall be free to provide this education in their homes or in private schools or in schools recognised or established by the State.

$3-1^{\circ}$ The State shall not oblige parents in violation of their conscience and lawful preference to send their children to schools established by the State, or to any particular type of school designated by the State.

$2^{\circ}$ The State shall, however, as guardian of the common good, require in view of actual conditions that the children receive a certain minimum education, moral, intellectual and social.

4 The State shall provide for free primary education and shall endeavour to supplement and give reasonable aid to private and corporate educational initiative, and, when the public good requires it, provide other educational facilities or institutions with due regard, however, for the rights of parents, especially in the matter of religious and moral formation (Ireland, 2015). 
O texto constitucional, além de garantir a primazia da decisão da família sobre a educação dos filhos, garante que o Estado não poderá violar a consciência e as preferências das famílias exigindo que seus filhos frequentem escolas estatais. Ainda que assegure às novas gerações o acesso a um mínimo de educação, este poderá ocorrer em casa, em instituições públicas ou privadas.

A Constituição caracteriza como 'escolas nacionais' todas as instituições financiadas pelo estado, ainda que de propriedade e gestão privada. No caso das confessionais, a imensa maioria, o Artigo 42 ressalta o direito à liberdade religiosa dos estudantes.

$\mathrm{Na}$ Irlanda, é função do Ministério da Educação determinar a política educacional nacional e definir um currículo mínimo; autorizar o funcionamento e financiar escolas reconhecidas, monitorar e avaliar a qualidade, a eficiência e a eficácia de todas as escolas e dos setores que arrendem terras ou edifícios com o propósito de estabelecer uma escola. Segundo o documento Education Act de 1998, cabe ainda ao Departamento de Educação e Ciência da Irlanda (DES), órgão do Ministério da Educação, pagar diretamente os salários de todos os professores das escolas subvencionadas, aprovar pedidos para o estabelecimento de novas escolas primárias, contribuir para os custos das instalações escolares e inspecionar periodicamente as unidades escolares. (Ireland, Education Act, 1998). Ao Ministro da Educação cabe, em concordância com o Ministro das Finanças, determinar anualmente os critérios pelos quais qualquer classe ou classes de escolas ou centros reconhecidos para a educação serão financiados com verbas destinadas pelo Oireachtas. (Ireland, Education Act, 1998)

O Parlamento Nacional (Oireachtas) é composto pelo presidente e duas casas legislativas: Dáil Éireann (Câmara dos Deputados) e Seanad Éireann (Senado), cujas funções e poderes derivam da Constituição da Irlanda, promulgada em 1 de julho de 1937. As Câmaras do Oireachtas situam-se em Leinster House/Dublin e são responsáveis por normatizar a educação no país?.

De acordo com pesquisa em documentos oficiais, em 2017, a educação básica organizava-se em quatro níveis: pré-escola (crianças entre 3 e 4 anos sem frequência obrigatória); seis anos de educação primária obrigatória (crianças entre 4 a 12/13 anos de idade); escola secundária composta, por dois ciclos (Junior e Senior), sendo que apenas o primeiro ciclo é obrigatório. A partir do segundo ciclo do secundário diferenciam-se as trajetórias escolares. A oferta escolar, ainda que gratuita, deriva de provedores privados subsidiados pelo poder público (Ireland, Education Act, 1998). 
Regulada por Lei Nacional, as escolas nacionais subvencionadas são impedidas de cobrar mensalidades ou taxas, salvo como contribuição voluntária. Em 2016, a subvenção mensal por aluno nas escolas primárias correspondeu a $\epsilon 170^{8}$. Além desse subsidio per capita e do pagamento de professores, o Estado repassa recursos para a manutenção das escolas e para a aquisição de livros e material escolar; nesse caso, entre 15 e 21 Euros por aluno. Escolas que atendiam estudantes considerados vulneráveis economicamente ou com necessidades educativas especiais recebiam complementação no valor per capita. Já as escolas privadas não recebem nenhum tipo de subsídio.

Dados da OCDE, publicados em 2017, indicavam que a Irlanda gastava ${ }^{9}$ por aluno abaixo da média internacional, ocupando a $19^{a}$ posição dentre os países que integram o levantamento da organização. No caso da educação primária, os dados mantinham o país na $19^{a}$ posição desde 2013. De acordo com o relatório, a média de gasto público por aluno/ano na educação primária equivalia a $€ 6.464$, sendo que a média dos países da OCDE foi $€ 7.233$; no ensino secundário o valor anual praticado pelo governo irlandês consistiu em cerca de $€ 8.200$, enquanto a média encontrava-se entre 68.300. Ainda de acordo com a mesma Organização, na Irlanda, 97\% dos fundos públicos para o ensino primário eram destinados a escolas "públicas", ou seja, as escolas nacionais, enquanto na média da OCDE esse repasse equivalia a 93\%. No ensino secundário, a Irlanda destinou 93\% dos fundos públicos para escolas públicas/nacionais, equiparando-se à média praticada pelos países da OCDE. (OCDE, 2017, Table B3.1.a)

\section{ADMISSÃO DE ALUNOS: INDAGANDO SOBRE COMO SE ESCOLHE A ESCOLA}

Em relação ao tipo de mantenedora, o DES classifica as escolas primárias nacionais, como confessional, inter-confessional e multi-confessional podendo ofertar o ensino em inglês ou irlandês (gaélico) ${ }^{10}$.

Por confessional entende-se a escola vinculada a uma única comunidade religiosa e que oferece educação religiosa de acordo com as tradições, práticas e crenças dessa comunidade religiosa especifica. Escolas interconfessionais correspondem às escolas que se encontram sob tutela de mais de uma comunidade

$8 \quad$ Algo em torno de $\mathrm{R} \$ 680,00$ em valores de 2018.

9 Gastos de educação abrangem as despesas com escolas, universidades e outras instituições de ensino públicas e privadas. Gastos incluem instruções e auxiliar de serviços para estudantes e famílias fornecidas através de instituições de ensino. Gastar é mostrada em USD por aluno e em percentagem do PIB (OCDE, 2017). 
religiosa. Já as escolas multiconfessionais, no contexto irlandês, são aquelas que não fornecem educação religiosa como parte de seu currículo e escolas que fornecem educação sobre religiões diferentes por período determinado e em função das solicitações dos pais. Tais escolas podem funcionar sob distintos ethos institucionais, neste contexto, entendidos como o conjunto de valores que propagam $^{11}$.

A Tabela apresenta, em período selecionado, o total de escolas primarias nacionais irlandesas por ethos institucional.

Tabela 1 - Total de escolas primárias por ethos institucional*. Ano letivo 2012 e 2017

\begin{tabular}{|c|c|c|}
\hline Ethos institucional & Total de escolas -2012 & Total de escolas - 2017 \\
\hline Católica & 2.884 & 2.794 \\
\hline Irlandesa & 180 & 175 \\
\hline Multiconfessional & 73 & 106 \\
\hline Presbiteriana & 14 & 15 \\
\hline Interconfessional & 8 & 18 \\
\hline Mulçumana & 2 & 2 \\
\hline Metodista & 1 & 1 \\
\hline Judaica & 1 & 1 \\
\hline Quaker & 1 & 1 \\
\hline Outras & 1 & 3.115 \\
\hline Total & 3.165 & $2017), 8$. \\
\hline
\end{tabular}

Fonte: As autoras, com base em Darmody, Smyth e McCoy (2012), p.2 e Tickner (2017), p.8.

A primeira informação a destacar refere-se à proporção de escolas primárias católicas em relação às demais: 89\%, em 2017. Destaca-se ainda a diminuição, no período, no número total de escolas em funcionamento (50 a menos), ao mesmo tempo em que se observa o crescimento de escolas multi e interconfessionais e a diminuição no número de escolas católicas e irlandesas.

Considerando o que no país se caracteriza como ethos institucional, $\mathrm{O}^{\prime}$ Mahony (2008), em survey para Conferência Episcopal de 2008, assinalava que a concentração da matrícula na escola católica associava-se, na maioria das vezes, à falta de opção enfrentada pelos pais, tendo em vista o fato de que, na proximidade da residência, a única escola disponível é a católica. Para o autor, esta é a razão para que, em muitos casos, pais não-católicos enviem seus filhos para uma escola com

11 Disponível em https://www.education.ie/en/Schools-Colleges/Information/Diversity-ofPatronage/. Acesso em setembro de 2017. 
essa denominação. Ainda assim, a maioria dos participantes no estudo afirmou que a escola frequentada pelo filho correspondia à primeira escolha, pois a distância de casa foi considerada fator determinante para a escolha. Por outro lado, o mesmo estudo indicou que, enquanto 37\% escolheriam uma escola da mesma religião, $10 \%$ escolheriam uma escola laica e, dentre esses, aqueles oriundos de outros Estados-membros da União Europeia foram 3,8 vezes mais propensos a escolher uma escola não religiosa em comparação com os seus homólogos irlandeses.

Darmody, Smyth e McCoy (2012) confirmam que a matrícula nas escolas primárias se dão em função da proximidade da casa, em geral em escola paroquial local, na qual crianças que tenham irmãos ou pais como ex-alunos são priorizadas. Já para Cohen-Zada e Sander (2007), alguns pais podem enviar seus filhos para escolas confessionais com vistas a preservar a identidade religiosa da família, enquanto outros procurariam escolas que não promovessem um sistema de fé específico. Para esses autores, estudos desenvolvidos nos EUA mostraram que tanto a religião, quanto a religiosidade impulsionam a demanda para escolas privadas, sejam essas católicas, protestantes ou mesmo não confessionais (COHEN-ZADA, SANDER; 2007).

No caso irlandês,

\begin{abstract}
"A maior diversidade étnica e cultural entre a população de estudantes na Irlanda contribuiu para uma demanda crescente de escolas multi-confessionais. O movimento The Educate Together na República da Irlanda é uma resposta à vontade de alguns pais de oferta de um novo tipo de escola, centrada em um ambiente inclusivo, e no respeito ao aluno. Este setor tem se expandido rapidamente desde que foi criado em 1978. Agora existem 60 escolas em 19 condados". (Darmody, Smyth e McCoy, 2012, p. 3 - Tradução livre das autoras) ${ }^{12}$.
\end{abstract}

Formalmente, as políticas de admissão às escolas na etapa obrigatória devem cumprir o disposto na seção 7 do Equal Status Act 2000, segundo o qual os pais podem apelar às instâncias superiores caso a escola se recuse a matricular uma criança. Entretanto, geralmente, as escolas confessionais dão prioridade a seus correligionários, como indica a literatura consultada e as entrevistas realizadas, apresentadas no próximo item. Tal perspectiva é ainda confirmada por documento divulgado pela OCDE, segundo o qual

\footnotetext{
12 "Increased cultural and ethnic diversity among the student population in Ireland has contributed to a growing demand for schools that are multi-denominational in character. The Educate Together movement in the Republic of Ireland is one response to some parents' wishes for the provision of a new type of school, centred on offering an inclusive, learner-centred environment of equal respect. This sector has expanded rapidly since it was established in 1978. There are now 60 schools in 19 counties.
} 
Se puderem escolher a escola para seu filho, é mais provável que os pais considerem mais importantes critérios como 'ambiente escolar' e 'boa reputação' da escola do que 'alta realização acadêmica' (OECD 2013, p.128- tradução livre).

Já Lubienski e Lee (2016) consideram que “pais” não são uma categoria monolítica, pois alguns escolhem as escolas com base na qualidade acadêmica, enquanto outros tendem a enfatizar os custos em termos de proximidade, taxa de matrícula ou transporte, por exemplo. Entendem que são poucas as informações a respeito de como os pais praticam suas preferências escolares e sobre como as escolas respondem a essas práticas, inclusive no que tange a recursos financeiros. Indicam a necessidade de estudos que considerem as relações espaciais, articuladas a obstáculos físicos e sociais, por exemplo.

Em diálogo com as problematizações assinaladas pela literatura, as entrevistas realizadas neste estudo buscaram ampliar informações sobre dois aspectos: os critérios adotados pelas famílias para a escolha da escola de seus filhos e filhas e o tipo de contrapartida exigido pelas escolas escolhidas para admissão dos estudantes.

\section{COMO SE ESCOLHEM AS ESCOLAS: DIÁLOGO COM MÃES RESIDENTES NA REGIÃO DE DUBLIN.}

Segundo informações governamentais, Dublin é a capital da República da Irlanda desde sua proclamação em 1949, depois de fortes e sangrentos enfrentamentos com o governo inglês durante a luta por sua soberania, esta autoproclamada em 1937. Desde então, a Irlanda tornou-se uma democracia parlamentar.

O governo divide-se entre os governos central e as autoridades locais, neste caso exercido por Conselhos Municipais eleitos que se articulam a representantes governamentais nomeados pelo Governo Central. As competências dos Conselhos Municipais incluem planejamento, infraestrutura de transporte, serviços sanitários, segurança pública (principalmente bombeiros) e fornecimento de bibliotecas públicas. Já a educação está diretamente vinculada ao Ministerio de Educação e Desenvolvimento, parte integrante do governo central.

Em Dublin, existem quatro autoridades locais, nomeadamente Dublin City Council, Fingal County Council, South Dublin County Council and Dun Laoghaire Rathdown County Council. As escolas escolhidas pelas entrevistadas encontram-se em Dublin City Council, Dun Laoghaire Rathdown e South Dublin County Council, condição que ilustra variação regional. 
A seleção das entrevistadas levou em consideração três critérios: filhos matriculados em escolas na etapa obrigatória; residirem em diferentes distritos de Dublin e frequentarem escolas com diferentes ethos institucionais. Além disso, deveriam manifestar interesse em colaborar com a pesquisa, expresso em consentimento formalmente firmado.

A escolha dessas pessoas decorreu de contatos efetuados pela pesquisadora residente em grupos de mães e local de trabalho, uma vez que as escolas, inicialmente acionadas, não nos permitiram contatar as famílias. Frise-se, ainda, que o inquérito não se referia ao perfil das famílias uma vez que tratou de "introduzir, no escopo das investigações desenvolvidas, também a percepção dos usuários sobre a escola escolhida" (suprimido).

Entrevistaram-se cinco mulheres, todas com ensino superior completo, cujas respostas a respeito das sete escolas escolhidas para seus filhos e filhas estão organizadas no Quadro 1.

\section{Quadro1 - Síntese entrevistas sobre escolha da escola na etapa obrigatória.}

\begin{tabular}{|c|c|c|c|c|c|c|}
\hline Escola & $\begin{array}{l}\text { Estudantel } \\
\text { Gênero }\end{array}$ & $\begin{array}{c}\text { Critério para } \\
\text { a escolha }\end{array}$ & $\begin{array}{l}\text { Tipo de } \\
\text { Escola }\end{array}$ & $\begin{array}{l}\text { Formas de } \\
\text { contribuição }\end{array}$ & $\begin{array}{l}\text { Razões para } \\
\text { escolher } \\
\text { outra escola }\end{array}$ & $\begin{array}{c}\text { Exigências } \\
\text { da escola } \\
\text { para } \\
\text { matrícula }\end{array}$ \\
\hline A & $\begin{array}{l}1 \text { menina no } \\
\text { primário }\end{array}$ & $\begin{array}{c}\text { Proximidade } \\
\text { e existência } \\
\text { de vagas }\end{array}$ & $\begin{array}{c}\text { Pública/ } \\
\text { Católica } \\
\text { Para meninas }\end{array}$ & $\begin{array}{l}\text { Taxas para lanche; } \\
\text { Compra de } \\
\text { uniforme } \\
\text { (obrigatório); } \\
\text { Material escolar }\end{array}$ & $\begin{array}{l}\text { Laica } \\
\text { Mista }\end{array}$ & $\begin{array}{c}\text { Morar no } \\
\text { bairro }\end{array}$ \\
\hline B & $\begin{array}{l}2 \text { meninas } \\
\text { na mesma } \\
\text { escola }\end{array}$ & $\begin{array}{l}\text { Proximidade; } \\
\text { Mista; } \\
\text { Reputação } \\
\text { excelente }\end{array}$ & $\begin{array}{l}\text { Católica, } \\
\text { Pública } \\
\text { Mista }\end{array}$ & $\begin{array}{c}\text { Contribuição } \\
\text { voluntária de taxa } \\
\text { no começo do ano; } \\
\text { Participação } \\
\text { em atividades } \\
\text { comunitárias para } \\
\text { arrecadar fundos } \\
\text { para a biblioteca } \\
\text { (feiras de livro etc.); } \\
\text { Participação } \\
\text { em atividades } \\
\text { religiosas. }\end{array}$ & $\begin{array}{c}\text { Educate } \\
\text { together } \\
\text { (escola } \\
\text { multicultural) }\end{array}$ & $\begin{array}{c}\text { Certificado de } \\
\text { batismo } \\
\text { Residir na } \\
\text { localidade } \\
\text { da escola- } \\
\text { catchment } \\
\text { area }\end{array}$ \\
\hline C & $\begin{array}{l}1 \text { menina no } \\
\text { primário }\end{array}$ & $\begin{array}{c}\text { Proximidade } \\
\text { de casa }\end{array}$ & $\begin{array}{c}\text { Pública e } \\
\text { Laica } \\
\text { Para meninas }\end{array}$ & $\begin{array}{c}\text { Contribuição } \\
\text { voluntária; } \\
\text { Taxas lanche; } \\
\text { Compra de } \\
\text { uniforme e material } \\
\text { escolar }\end{array}$ & $\begin{array}{l}\text { Mista } \\
\text { Católica }\end{array}$ & $\begin{array}{c}\text { Proximidade } \\
\text { da casa }\end{array}$ \\
\hline D & $\begin{array}{l}1 \text { menino no } \\
\text { secundário }\end{array}$ & $\begin{array}{l}\text { Indicação } \\
\text { de familiar } \\
\text { professora }\end{array}$ & $\begin{array}{c}\text { Pública e } \\
\text { católica } \\
\text { Para meninos }\end{array}$ & $\begin{array}{l}\text { Contribuição } \\
\text { voluntária; } \\
\text { Taxas lanche; } \\
\text { Compra de } \\
\text { uniforme e material } \\
\text { escolar }\end{array}$ & $\begin{array}{l}\text { Mista e } \\
\text { católica }\end{array}$ & $\begin{array}{c}\text { Mudaram de } \\
\text { bairro para } \\
\text { garantir a } \\
\text { matrícula } \\
\text { na escola } \\
\text { desejada. }\end{array}$ \\
\hline
\end{tabular}




\section{Quadro1 - Síntese entrevistas sobre escolha da escola na etapa obrigatória.}

\begin{tabular}{|c|c|c|c|c|c|c|}
\hline Escola & $\begin{array}{l}\text { Estudantel } \\
\text { Gênero }\end{array}$ & $\begin{array}{c}\text { Critério para } \\
\text { a escolha }\end{array}$ & Tipo de Escola & $\begin{array}{l}\text { Formas de } \\
\text { contribuição }\end{array}$ & $\begin{array}{l}\text { Razões para } \\
\text { escolher } \\
\text { outra escola }\end{array}$ & $\begin{array}{l}\text { Exigências } \\
\text { da escola } \\
\text { para } \\
\text { matrícula }\end{array}$ \\
\hline$E$ & $\begin{array}{l}1 \text { menina no } \\
\text { primário }\end{array}$ & $\begin{array}{l}\text { Gratuita, } \\
\text { mista, } \\
\text { proximidade } \\
\text { de casa } \\
\text { e boa } \\
\text { reputação }\end{array}$ & $\begin{array}{c}\text { Pública/ } \\
\text { Católica/mista }\end{array}$ & $\begin{array}{c}\text { Não } \\
\text { mencionou } \\
\text { nada }\end{array}$ & $\begin{array}{l}\text { Escolheria } \\
\text { escola } \\
\text { pública, } \\
\text { mista e laica } \\
\text { e perto de } \\
\text { casa }\end{array}$ & $\begin{array}{c}\text { Declaração } \\
\text { de interesse } \\
\text { quando bebê, } \\
\text { declaração } \\
\text { de aceite do } \\
\text { ethos }\end{array}$ \\
\hline $\mathrm{F}$ & $\begin{array}{l}1 \text { menina } \\
\text { primeiro } \\
\text { ciclo do } \\
\text { secundário }\end{array}$ & $\begin{array}{l}\text { Privada } \\
\text { (paga), } \\
\text { perto da } \\
\text { casa, mista, } \\
\text { laica e boa } \\
\text { reputação. }\end{array}$ & $\begin{array}{c}\text { Privada/ } \\
\text { internacional, mista } \\
\text { e laica }\end{array}$ & $\begin{array}{c}\text { Paga } \\
\text { mensalidade, } \\
\text { matrícula } \\
\text { e materiais } \\
\text { escolares. }\end{array}$ & $\begin{array}{l}\text { Escolheria } \\
\text { escola } \\
\text { pública, } \\
\text { mista e laica } \\
\text { e perto de } \\
\text { casa }\end{array}$ & $\begin{array}{c}\text { Declaração } \\
\text { de interesse } \\
\text { pagamento } \\
\text { taxa. }\end{array}$ \\
\hline G & $\begin{array}{c}\text { Uma criança } \\
\text { (Não } \\
\text { especificado) }\end{array}$ & Proximidade & $\begin{array}{l}\text { Escola mista; } \\
\text { multiconfessional } \\
\text { e língua gaélica } \\
\text { como segundo } \\
\text { idioma }\end{array}$ & $\begin{array}{l}\text { Taxas para } \\
\text { lanche e } \\
\text { compra de } \\
\text { uniforme }\end{array}$ & $\begin{array}{l}\text { Escola } \\
\text { católica }\end{array}$ & $\begin{array}{c}\text { Pré-matrícula } \\
\text { da criança } \\
\text { ainda bebê }\end{array}$ \\
\hline
\end{tabular}

Fonte: autoras, com base nas entrevistas concedidas entre 2017 e 2018.

As entrevistas versaram sobre sete diferentes tipos de escolas: seis públicas e uma particular. No primeiro bloco, duas eram multiconfessionais e quatro católicas. Quatro eram mistas (três públicas/católicas e particular), duas femininas e uma para meninos. A escola particular, além de laica era internacional e uma das escolas públicas oferecia o ensino em gaélico.

Um primeiro aspecto a considerar, a partir dos depoimentos, refere-se à matrícula em escolas próximas à residência como critério recorrente e como decorrência de exigências das escolas, o que levou uma das famílias a mudar de bairro e outras a lamentarem a inexistência de escolas laicas e ou mistas nos bairros em que residem.

Sobre o ethos escolar, interessa destacar que a insatisfação com a escola atual não se atrelou ao grau de escolaridade das crianças, mas à impossibilidade de escolher o tipo de escola desejado. Em todos os casos, a escola frequentada, mesmo quando paga, não atendia às expectativas das famílias. Especialmente no que tange à religião, expressa na demanda por escolas laicas ou multiconfessionais dentre os que se encontram em escolas católicas. Também no que concerne à segregação por gênero, há um apelo por escolas mistas. A esses critérios agregase a gratuidade e a proximidade da residência. Interessa frisar que a escolha por escolas de boa reputação acadêmica foi identificada em três respostas para a opção pela escola atual, mas não aparece como requisito para a escola desejada. 
Elemento ainda a considerar diz respeito às exigências das escolas para a matrícula. Destas se destacam a pré-matrícula do futuro estudante ainda em bebê, como mecanismo para "reserva de vaga" e a entrega de atestado de batismo para matrícula a uma das escolas católicas.

Todas as entrevistadas consideram que as escolas públicas exigem o pagamento de alguma contrapartida, seja por exigir a compra de uniformes obrigatórios e tidos como caros, lanches ou livros e materiais escolares complementares, seja por cobrar contribuição em dinheiro, ainda que de forma voluntária.

\section{INDICAÇÕES EM FORMA DE SÍNTESE}

O primeiro aspecto a considerar é que estudos a respeito de sistemas de ensino estruturados a partir do provimento privado, apresentam-se como elemento importante para a composição de um quadro de análise sobre políticas educacionais e sobre proposições de políticas assentadas na escolha de escolas com subsídio público. Isso porque, vêm-se ampliando medidas dessa natureza para novos contextos, com o estímulo de diversos think tanks nacionais e internacionais. A exemplo, cita-se a recente declaração de Bill Gates à imprensa americana que $15 \%$ dos US $\$ 1,7$ bilhão destinados à educação pela Fundação Gates serão destinados ao financiamento de escolas charter para estudantes com necessidades especiais (BALINGIT, 2017). No Brasil assiste-se à proposição de programas de introdução de voucher para merenda e transporte como em São Paulo, a generalização de programas de "bolsas" para frequência à educação infantil implantados em dezenas de municípios paulistas (DOMICIANO, 2012; BORGHI et al; 2014; OLIVEIRA, 2018) ou ainda de programas de transferência da gestão de escolas públicas para organizações privadas.

Concordando com Lynch e Moran (2006), considera-se que a ampliação de políticas dessa natureza potencializa estratégias para que a oferta da educação básica se transforme em oportunidade de expansão de "mercados educacionais", tendendo a conformar tradicionais formatos de educação comunitária, cooperativa, ou mesmo confessional a modelos de oferta educativa orientada por esses mercados.

Um segundo aspecto, decorrente do estudo do sistema de educação irlandesa, diz respeito ao sentido atribuído, por aquela sociedade, à escola pública: instituições educacionais reguladas e financiadas pelo poder público, mas cuja propriedade ou filiação é de natureza privada. Ainda que o tema não seja passível de desenvolvimento no escopo deste artigo, é certo que um sistema educacional no qual inexista, por definição legal, escola estatal e que a etapa de escolaridade 
obrigatória tenha a frequência gratuita assegurada, parece constituir-se em relevante objeto de investigação a medida em que suscita indagações sobre se sistemas educativos organizados com essas bases (pública não estatal) favorece ou dificulta a oferta educativa por organizações com fins de lucro.

Em relação à amplitude do modelo de escolha, as entrevistas indicam que, contrariamente ao apresentado por Fox e Buchanan (2008), as matrículas na região de Dublin são georreferenciadas e associadas a determinado catchment area.

Indicam também que a escolha da escola se associa a fatores como a religião proclamada e a disponibilidade de vagas, condições que geram diferenças no acesso à escola e no tipo de escola disponível e em relativa competição entre as famílias percebidas na antecipação de reservas de vagas para futuros estudantes, enquanto esses são ainda bebês.

Tais diferenciações expressam-se nas estratégias de escolha das famílias e na seleção velada de estudantes praticada por escolas, mesmo em condições onde o georreferenciamento não é o principal mecanismo para a matrícula, como o caso irlandês. Lubienski (2000) considera que a escolha das escolas porta uma preocupação das famílias com a competitividade futura de seus filhos no seletivo sistema educacional. Essa diferenciação pode ser percebida nas estratégias familiares pela busca de uma escola melhor, como a mudança de residência ou a matrícula em escola privada.

Alguns depoimentos confirmam tendência identificada por Darmody, Smyth eMcCoy (2012), segundo a qual o movimento Educate Together expressa o desejo de famílias por escolas mais inclusivas, respondendo ao crescimento da diversidade cultural e étnica no pais. Trata-se de escolas multiconfessionais e mistas não dirigidas por entidades religiosas ou a essas vinculadas. Nessa mesma direção, em maio de 2018, o ministro da educação em exercício anuncia um processo de consulta a pais de algumas localidades a respeito de suas preferências pelo tipo de escola oferecido ${ }^{13}$.

Registra-se que as diferenças no padrão educacional, decorrentes da diversidade no ethos e de diferenças na localização das escolas, tende a ser minimizado pela manutenção de exigências comuns para o pagamento dos professores e de um currículo nacionalmente definido. Ainda assim, o convite ao aprofundamento desses temas continua em pauta.

Por fim, indica-se que se aproximar, na forma de estudo, de campos empíricos diversos, como o caso irlandês, sublinha a importância das singularidades no estudo das políticas educacionais, favorecendo que, além das contradições

13 <https://www.irishtimes.com/news/education/parents-to-be-surveyed-on-demand-for-noncatholic-schools-1.3510333>. Acesso maio/2018. 
próprias do campo da política - passíveis de percepção quando de estudos empíricos (FREY, 2000) -, tendências globais, como a privatização, possam ter suas consequências compreendidas em diálogo com as condições objetivas e historicamente construídas em cada contexto.

\section{REFERENNCIAS}

ADRIÃO, T. Dimensões e Formas da Privatização da Educação no Brasil: caracterização a partir de mapeamento de produções nacionais e internacionais. Currículo sem fronteiras. v. 18, n. 1, p. 8-28, jan./abr. 2018. Disponível em <http://www.curriculosemfronteiras.org/vol18iss1articles/ adriao.pdf $>$. Acesso em 03 de agosto de 2018.

ADRIÃO, T. A privatização dos processos pedagógicos: grupos editorias e os negócios da educação básica In: O Negócio da educação: a ventura das universidades privadas na terra do capitalismo sem risco.1 ed. São Paulo: Olho d'Água e FEPESP, 2017, v.1, p. 129-144.

ADRIÃO, T. Escolas charters nos EUA: contradições de uma tendência proposta para o Brasil. Educação e Filosofia, v. 28, 2014. < http://www.seer. ufu.br/index.php/EducacaoFilosofia/article/view/24613>. Acesso em 03 de agosto de 2018

ADRIÃO, T. Indicações e Reflexões sobre as Relações entre Esferas Públicas e Privadas para a Oferta Educacional no Brasil. Políticas Educativas. v.3, 2009. Disponível em http://seer.ufrgs.br/index.php/Poled/article/view/22531

APPLE, M. W.Educando à Direita: Mercados, Padrões, Deus e Desigualdade. São Paulo: Cortez, 2003.

ARCHBALD, D. A. School Choice, Magnet Schools, and the Liberation Model: An Empirical Study. Sociology of Education, Vol. 77, No. 4 , pp. $283-$ 310, Oct, 2004

BALINGIT, M. Billionaire Bill Gates announces a $\$ 1.7$ billion investment in U.S. schools. In <https://www.washingtonpost.com/ local/education/billionaire-bill-gates-announces-a-17-billion-investment-inus-schools/2017/10/19/9938f11c-b4eb-11e7-a908-a3470754bbb9_story. html?noredirect $=$ on\&utm_term $=$. ce8425118cfc $>$. 2017. Acesso em: ago. 2018. 
BORGHI, R. et al. Subsídios públicos para instituições privadas de educação infantil. In: SILVA, Maria Vieira e MEDINA, Sarita. (Org.). Trabalho Docente e Políticas Educacionais para a educação infantil: desafios contemporâneos. 1ed. Uberlandia: EDUFU, 2014, v. 1, p. 131-149;

BUCHANAN, N; FOX, R. Every school a school of choice: school choice in Ireland as viewed through American eyes. Irish Educational Studies, Volume: 27 Edição: 3 Páginas: 267-279, 2008.

COHEN-ZADA, D. AND SANDER, W. Religion, religiosity and private school-choice: Implications for estimating the effectiveness of private schools, Journal of Urban Economics, V. 64, n.1, p. 85-100, 2007.

DARMODY, M; SMYTH,E; MCCOY, S. School Sector Variation Among Primary Schools in Ireland. Department of Children and Youth Affairs, 2012; 72p. In < https://www.esri.ie/pubs/BKMNEXT221.pdf>.

DEPARTMENT OF EDUCATION AND SKILLS. Advancing School Autonomy in the Irish School system. Research Paper. December 2015. In <https://www.education.ie/en/Schools-Colleges/Information/AdvancingSchool-Autonomy-in-Ireland/School-Autonomy-Research-Paper.pdf>. Acess: dec. 2017.

DOMICIANO, C. A. O Projeto "Nave-Mae" no município paulista de Campinas e os objetivos para o Desenvolvimento Sustentável do Milênio: tendências de privatização da educação infantil. Políticas Educativas, Porto Alegre, v.6, n.1, p.90-106, 2012.

EDWARDS JUNIOR, Brent; HALL, Stephanie M.. Escolas charter: gestão de professores e aquisição de recursos na Colômbia. Cad. Pesqui., São Paulo , v. 47, n. 164, p. 442-468, June 2017 . Available from <http://www.scielo.br/ scielo.php?script $=$ sci_arttext\&pid $=$ S0100-15742017000200003\&lng $=$ en\&nrm $=i$ so>. Access 01 Aug. 2018.

FOX, R e BUCHAMAN, N. School Choice in the Republic of Ireland An Unqualified Commitment to Parental Choice, 2008. <https://www. researchgate.net/publication/253420181_School_Choice_in_the_Republic_of_ Ireland $>$. 
FREITAS, Luiz Carlos de. Os reformadores empresariais da educação e a disputa pelo controle do processo pedagógico na escola. Educ. Soc., Campinas, v. 35, n. 129, p. 1085-1114, Dec. 2014 . Disponível em: <http://www. scielo.br/scielo.php?script $=$ sci_arttext\&pid $=$ S0101-73302014000401085\&lng $=$ e n\&nrm=iso $>$. access on 18 July 2015. http://dx.doi.org/10.1590/ES010173302014143817 ;

FREY, K. Políticas públicas: um debate conceitual e reflexões referentes à prática da análise de políticas públicas no Brasil. Planejamento e Políticas Públicas, IPEA- Brasília, v. 21, p. 211-259, 2000.

IRELAND. CONSTITUTION OF IRELAND. In < https://www.constitution. ie/Documents/Bhunreacht_na_hEireann_web.pdf $>$. Acesso 05 de janeiro de 2018

IRELAND. EDUCATION ACT. 23 December, 1998. Disponível em https:/ / www.oireachtas.ie/en/bills/bill/1997/67/. Acesso em 14 de agosto 2018.

IRELAND. NATIONAL SCHOOL ANNUAL CENSUS 2016/2017. < https:/ / www.education.ie/en/Publications/Statistics/Data-on-Individual-Schools/>. Acesso 05 de janeiro de 2018

JHA, T ; BUCKINGHAM, J. Free to choose charter schools: how charter and for-profit schools can boost public education. National Library of Australia Cataloguing-in-Publication, 2015. <https://www.cis.org.au/app/ uploads/2015/08/rr6.pdf>. Acess on: 02 jan. 2018.

KLEES, $S$ et al. The World Bank and education. Critiques and alternatives. Roterdam/Boston/ Taipei: Sense Publishers:, 2012.

LUBIENSKI, C.; YOON, E. Introduction to the Special Issue: Studying School Choice in Canada. Education Policy Analysis Archives. Volume 25 Number 37 April 24, 2017.

LUBIENSKI, C., \& WEITZEL, P. Choice, Integration, and Educational Opportunity: Evidence on Competitive Incentives for Student Sorting. The Journal of Gender, Race \& Justice, v.12, n.2, p.351- 376, 2009 
LUBIENSKI, C. e LEE, J. Geo-spatial analyses in education research: the critical challenge and methodological possibilities. In Geographical Research, p.1-11, 2016

Lubienski, C. Whither the Common Good? A Critique of Home Schooling. Peabody Journal of Education, v.75, n.1-2, p. 207-232, 2000. DOI: 10.1080/0161956X.2000.9681942

LYNCH, K; MORAN, M. Markets, schools and the convertibility of economic capital: the complex dynamics of class choice. British Journal of Sociology of Education, v. 27, n.02, p. 221-235, 2006.

OCDE, Education at Glance, 2017. <http://gpseducation.oecd.org/CountryP rofile?plotter $=$ h5\&primaryCountry $=$ IRL\&treshold=10\&topic $=E O>$. Acesso 12 de janeiro de 2018

OCDE. Governement at a Glance 2015. Disponível em https://www.oecd. org/gov/Ireland.pdf. Acesso em: 03 jan. 2018.

OCDE. PISA 2012 Results: What Makes Schools Successful? Resources, Policies and Practices (Volume IV), PISA, OECD Publishing, 2013.

O' MAHONY, E. Factors Determining School Choice Report on a survey of the Attitudes of Parents of Children attending Catholic Primary Schools in Ireland. Irish Bishops' Conference, 2008.

OLIVEIRA, J. dos Santos. Subsídios públicos à iniciativa privada: o caso do Programa Bolsa Creche e escolas autogestionadas. 2018 Tese (Doutorado em Educação) - Universidade Estadual Paulista Júlio de Mesquita Filho, 2018.

PATRINOS, H. A., BARRERA-OSORIO, F., GUÁQUETA, J. The role and impact of public-private partnerships in education, 2009 Retrieved from http://www.voced.edu.au/content/ngv33776

PIOVESAN, A. E TEMPORINI, E. R. Pesquisa exploratória: procedimento metodológico para o estudo de fatores humanos no campo da saúde pública. Revista de Saúde Pública, v. 29, n.4, 318-325, 1995. < https://dx.doi. org/10.1590/S0034-89101995000400010>. Acesso 09 de janeiro de 2017 
POLIT, D.F.; BECK, C.T.; HUNGLER, B.P. Fundamentos de Pesquisa em Enfermagem: métodos, avaliação e utilização. 5 ed. Porto Alegre: Artmed, 2004

SCOTT, J. The Politics of Venture Philanthropy in School Charter. Policy and Advocacy, Educational Policy, 2009.

THEODORSON, G. A.; THEODORSON, A. G. A modern dictionary of sociology. London, Methuen, 1970.

TICKNER, N. Interesting Facts - First Look at Data from POD, 2016/2017. February 2017. < https://www.education.ie/en/Publications/Statistics/PrimaryOnline-Database-POD-/POD-Interesting-Facts-First-Look-at-Data-fromPOD-2016-2017.pdf>. Acesso em: jun. 2018.

\section{SITES CONSULTADOS:}

http://www.curriculumonline.ie/Senior-cycle/Curriculum Acesso em: jul. 2017 e janeiro 2018.

http://www.citizensinformation.ie/en/education/the_irish_education_system/ overview_of_the_irish_education_system.htmlacesso Acesso em: jul. 2017

https://www.irishtimes.com/news/consumer/the-high-price-of-ireland-s-freeeducation-1.2280416 Acesso em: jun. 2017.

https://www.education.ie/en/Publications/Estimates/2016-Budget-MainFeatures.pdf Acesso em: jun. 2017.

http://www.oireachtas.ie/documents/bills28/acts/1998/a5198.pdf Acesso em: jan. 2018

http://www.cso.ie/en/interactivezone/visualisationtools/infographics/ Acesso em: jun. 2017. http://www.oireachtas.ie/parliament/about/>

https://www.constitution.ie/Documents/Bhunreacht_na_hEireann_web.pdf>. Acesso 05 de janeiro de 2018 
http://archive.constitution.ie/reports/ConstitutionofIreland.pdf Acesso em: jul. 2017.

http://www.citizensinformation.ie/en/education/primary_and_post_primary_ education/going_to_primary_school/ownership_of_primary_schools.html Acesso em: jun. 2017. www.education.ie/en/Schools-Colleges/Information/ Diversity-of-Patronage

THERESA MARIA DE FREITAS ADRIÃO possui graduação em pedagogia pela USP(1988), mestrado(1995) e doutorado (2001) em Educação pela Universidade de São Paulo. Atualmente é professora Livre Docente da Faculdade de Educação da UNICAMP. Desenvolveu dois estágios pós-doutorais: Orealc- UNESCO (2004-05) e University of Maryland (2012-13) Tem experiência na área de Educação, com ênfase em Administração Educacional, desenvolvendo pesquisas sobre aspectos relacionados à interface entre o financiamento e a gestão da educação básica e relações entre o público e o privado no campo educacional. Coordena o Grupo de Estudos e Pesquisas em Política Educacional (GREPPE)/ Unicamp. Integra a Associação Nacional de Financiamento da Educação (Fineduca) e Coordena o Grupo de Trabalho 5: Estado e Política Educacional da ANPED. E-mail: theadriao@gmail.com

JULIANA DE PAULA EDUARDO AZEVEDO possui graduação em Psicologia pela Pontifícia Universidade Católica de São Paulo (1997) e Aperfeiçoamento em Psicologia Clínica pela Pontifícia Universidade Católica de São Paulo (1999). Atualmente é psicóloga permanente da Health Service Executive. Tem experiência na área de Psicologia, com ênfase em Psicologia do Ensino e da Aprendizagem. 